\title{
A INFLUÊNCIA DA BACIA HIDROGRÁFICA NO CLIMA URBANO DA AMAZÔNIA: ANÁLISE DO CLIMA NA BACIA DO IGARAPÉ AMBÉ NO PERÍMETRO URBANO DE ALTAMIRA - PA, NO PERÍODO DE IMPLANTAÇÃO DA UHE BELO MONTE, 2011 À 2015
}

\author{
Alexandre Augusto Cardoso Lobato ${ }^{(a)}$, Paulo Marcio Sousa Goveia ${ }^{(b)}$, Thiago Silva dos \\ Santos $^{(\mathrm{c})}$, Wellington de Pinho Alvarez ${ }^{(\mathrm{d})}$ \\ (a) Bolsista do Laboratório Integrado de Geotecnologia (LABIGEO), Universidade Federal do Pará \\ (UFPA), alexandrelobato.ufpa@gmail.com. \\ (b) Bolsista do Laboratório Integrado de Geotecnologia (LABIGEO), Universidade Federal do Pará \\ (UFPA), marciopaulogoveia@gmail.com. \\ (c) Bolsista do Laboratório Integrado de Geotecnologia (LABIGEO), Universidade Federal do Pará \\ (UFPA), thiagogeografiaatm@gmail.com. \\ (d) Docente da Faculdade de Geografia, Coordenador do Laboratório de Geotecnologia, Universidade \\ Federal do Pará (UFPA), walvarez@ufpa.br.
}

Eixo: Climatologia em diferentes níveis escalares: mudanças e variabilidade

\begin{abstract}
Resumo
O presente trabalho tem como objetivo analisar a temperatura $\left({ }^{\circ} \mathrm{C}\right)$ da superfície do perímetro urbano de Altamira - Pará e suas relação com a bacia do igarapé Ambé, neste o uso de geotecnologias, especialmente o sensoriamento remoto, na região do infravermelho termal dos sensores Landsat-5/TM e Landsat-8/OLI permitiu a espacialização da temperatura, bem como, sua relação com nova dinâmica espacial oriunda dos processos de implementação da Usina da Hidrelétrica de Belo Monte (UHEBM) no Rio Xingu.
\end{abstract}

Palavras chaves: Temperatura, Bacia hidrográfica, Paisagem, Espaço urbano.

\section{Introdução}

Sobre isso, é relevante sublinhar, que as características de homogeneidade das pequenas bacias hidrográficas fazem com que elas sejam muitas vezes utilizadas em pesquisas visando a obter melhor apreensão dos processos físicos, químicos e biológicos que intervêm no ciclo hidrológico. Logo, o conceito de bacia hidrográfica está associado ao tipo de estudo efetuado, aplicação e interpretação a partir dos dados nelas coletados (Paiva \& Paiva, 2001).

Na perspectiva da problematização do usos das bacias, (Genz \& Tucci, 1995), aponta que os principais impactos decorrentes do desenvolvimento de uma área urbana sobre os processos hidrológicos, estão associados à forma de ocupação da terra, e este, ao aumento das superfícies impermeáveis. Assim, as bacias urbanas necessitam ser planejadas visando seu uso futuro, contudo, a falta de planejamento adequado e as 


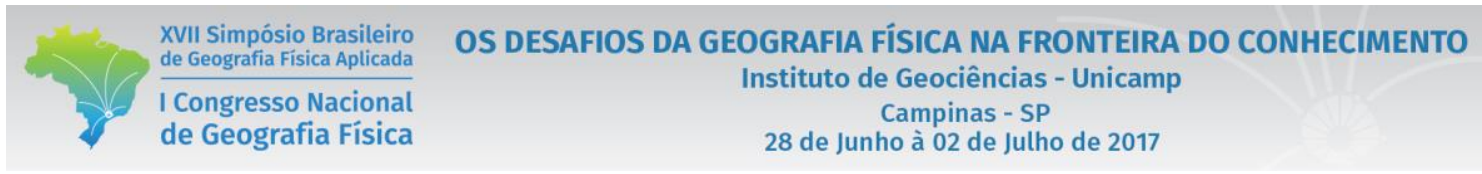

irregularidades na ocupação descontrolada tornam esta tarefa bastante difícil (Campana \& Tucci, 1994).

As bacias hidrográficas e seu complexo paisagístico podem ser fundamentais para regulação da temperatura e amenização climática no urbano. Relacionado a isso, este trabalho realizou análises temporais e espaciais da temperatura superficial do urbano e sua diferenciação na bacia hidrográfica do Rio Ambé, correlacionando-os a impactação causada pela Usina Hidroelétrica de Belo Monte (UHEBM) no urbano altamirense.

\section{Metodologia}

A sede do município de Altamira está localizada na mesorregião do sudoeste do paraense e à microrregião de Altamira, se caracteriza por concentrar a maior parte dos serviços e as demandas de vários municípios ao longo da BR-230 (Transamazônica) na referida mesorregião. A sede fica situada à margem esquerda do Rio Xingu, sendo localizada nas coordenadas $3^{\circ} 12^{\prime} 12^{\prime \prime} \mathrm{S}$ e $52^{\circ} 12^{\prime} 23^{\prime \prime} \mathrm{O}$. Está a 74 metros de altitude (IBGE), conforme o mapa 01. Esta segundo a classificação Köppen (1928), tem clima do tipo equatorial Am e Aw. O primeiro, predominante na parte norte do município, onde se localiza a sede municipal (Silva et al., 2009).

Mapa de Localização - Bacia do Igarapé Ambé, Altamira-PA.

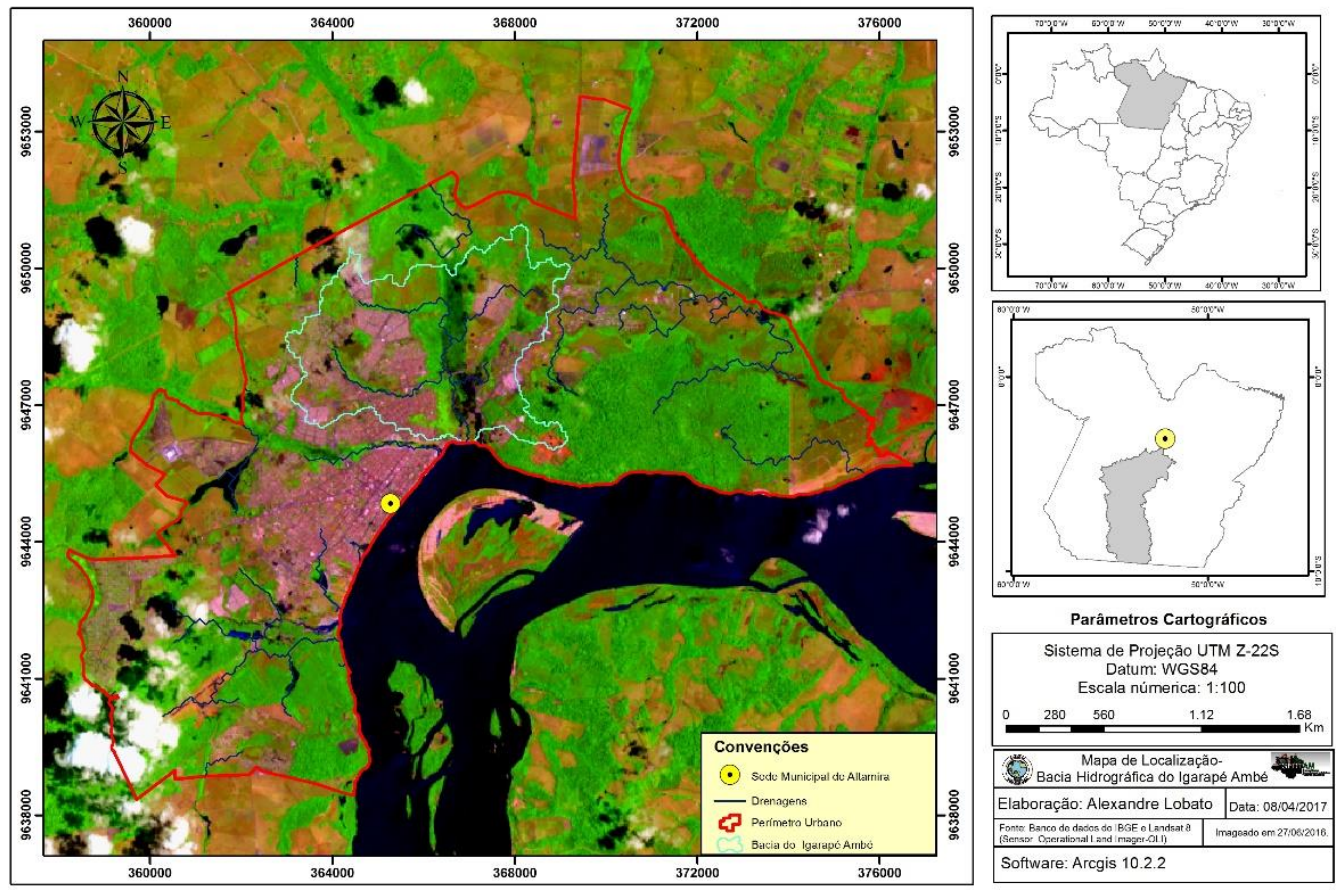

Mapa 1: Mapa de localização da bacia do Igarapé Ambé.

A área de estudo está localizada na bacia hidrográfica do rio Xingu, que por sua vez tem as dimensões de aproximadamente $531.250 \mathrm{Km} 2$ de área (IBGE), o que representa $13 \%$ 
do da Bacia Amazônica. Em seu médio curso existem três sub-bacias que atravessam o perímetro urbano de Altamira, as sub-bacias são do igarapé Altamira, Panelas e Ambé, qual destacaremos a última. Para este estudo foram realizados download de cenas do satélite Landsat 8 órbita/ponto 226/062, referente à data de 23/5/2015 e 23/02/2014 e, também, do satélite Landsat 5 órbita/ponto 226/062, referente ao ano de 25/06/2011 disponibilizadas pelo Sistema Geológico Americanos - USGS (http://earthexplorer.usgs.gov/).

O satélite Landsat 5, sensor Thematic Mapper possui 7 bandas espectrais, destas fizemos uso da Banda $6(10,4$ - 12,5 $\mu \mathrm{m})$, qual apresenta sensibilidade a fenômenos térmicos, especialmente no solo, vegetação, rocha e água. $\mathrm{O}$ satélite Landsat 8 possui o sensor OLI (Operational Land Imager) com 9 bandas espectrais e o sensor TIRS (Thermal Infrared Sensor) com 2 bandas espectrais no infravermelho termal, bandas 10 $(10.6-11.19 \mu \mathrm{m})$ e $(11.5-12.51 \mu \mathrm{m})$, com resolução espacial de $100 \mathrm{~m}$. A temperatura de superfície diz respeito ao fluxo de calor dado em função da energia que chega e sai do alvo, sendo de suma importância para o entendimento das interações entre a superfície terrestre e a atmosfera. A melhor faixa que permite maior transmissão da energia refletida pela Terra que alcança o sensor na região do infravermelho termal do espectro eletromagnético é o intervalo de 8,0 a 14,0 $\mu \mathrm{m}$ (Steinke et al., 2010).

As cenas foram tratadas no software ArcGis 10.2.2 utilizando-se dos algoritmos da temperatura de superfície do Landsat 5 a partir da conversão dos níveis de cinza da banda 6 em radiância espectral (TOA) através da equação 1 (USGS, 2014b).

$$
L \lambda=\left(\frac{\operatorname{Lmax} \lambda-\operatorname{Lmin} \lambda}{Q \operatorname{calmax}-Q \operatorname{calmin}}\right) *(Q \operatorname{cal}-Q \operatorname{cal})+\operatorname{Lmin} \lambda
$$

Em seguida foi realizado a transformação dos valores de radiância, em valores de temperatura Kelvin, através da equação 2.

$$
T S C=\frac{K 2}{\operatorname{In}\left(\frac{K 1}{L \lambda}+1\right)}
$$

Após este procedimento, os valores de temperatura Kelvin foram transformados em Celsius $\left({ }^{\circ} \mathrm{C}\right)$, usando o valor absoluto de 273,15 .

Para o Landsat 8, a banda utilizada para o processo de obtenção da conversão dos níveis de cinza é a banda 10, diferente do Landsat 5 , usa-se a equação 3 , sendo posteriormente 
utilizada a equação 2, e para transformar de Kelvin para Celsius $\left({ }^{\circ} \mathrm{C}\right)$ utiliza-se o valor absoluto $(273,15)$.

$$
\lambda=M l * Q c a l+A L
$$

Posteriormente, com a utilização das equações 1, 2 e 3, os dados obtidos foram processados e refinados com o auxílio dos (SIGs), resultando na diferença da temperatura em graus Celsius, nos anos de 2011 a 2015.

\section{Resultado e discussões}

Os estudos que envolvem o meio natural nos dias atuais têm chamado atenção de pesquisadores em diversas áreas do conhecimento, especialmente no espaço urbano relacionado aos processos de urbanização. Este por sua vez, se caracteriza como um abrigo da técnica, do trabalho e das amenidades (Corrêa, 1996). Em diversas situações a maneira como esse espaço é estruturado e organizado pode contribuir para precarização do bem-estar humano.

Sobre este contexto, Berque (1984) discorre que o estudo do meio natural, atualmente tem como objetivo entender as várias interações entre a sociedade e natureza, dentro de uma dinâmica dos fatores sociais, econômicos e culturais, desdobrando no conceito de paisagem, na perspectiva da herança (Ab'saber, 2003). Sobre isso, Ferreira (2010) discorre que as paisagens são temporais e espaciais, pois sempre resultam da observação e das ações das pessoas sobre o ambiente ao longo do tempo e espaço.

Não por acaso, Christofoletti (1993) enfatiza que o ser humano à medida que se desenvolve molda o meio natural, isto evidencia a importância de estudos referentes à paisagem, as quais devem servir de subsídios na elaboração de ação e planejamento. Nesse contexto, a paisagem urbana se destaca por ser um complexo formado de paisagens naturais e culturais, modificadas devido a elementos culturais, econômicos e sociais, sem acaso, a paisagem natural é fundamental à qualidade de vida urbana, isto porque, a paisagem natural pode contribuir positivamente no bem-estar climático.

A cidade gera um clima próprio (clima urbano) resultante da interferência de todos os fatores que se processam sobre a camada do limite urbano e que agem no sentido de alterar o clima na escala local (Monteiro, 1979). Desta forma, a paisagem natural e sua preservação podem contribuir para a dinâmica da vida urbana, particularmente na perspectiva climática. Isto porque, variações nas características da superfície urbana acabam por alterar o microclima local, mediante modificação do equilíbrio de energia 
entre a superfície e a camada limite, o que leva a formação de microclimas distintos (Offerle et al. 2005; Coutts et al. 2007, apud Alves, 2011), nesta linha, as bacias hidrográficas podem contribuir positivamente para amenidade do clima urbano (Christofoletti, 1980).

Assim sendo, é imperioso valorizar as paisagens naturais, na perspectiva dos cursos fluviais para análises do clima, para isso, as tecnologias de sensoriamento remoto e os sistemas de informações geográficas (SIG) são fundamentais. Pois, reconhecendo que, as tecnologias de sensoriamento remoto consistem na utilização conjunta de sensores, equipamentos para processamento e transmissão de dados, plataformas aéreas ou espaciais (Novo, 1998), é ponderável que a obtenção de imagens e outros tipos de informações da superfície terrestre através da captação e do registro da energia refletida ou emitida pela superfície da terra possa ser utilizada na análise do clima do urbano (Florenzano, 2002). Tal que em ambiente computacional os sistemas de informações geográficas compilem dados e represente-os, contribuindo decisivamente para analise espacial (Camara \& Monteiro, 2004).

Diante do exposto, apresenta-se uma análise multitemporal da temperatura superficial do perímetro urbano de Altamira - PA, nesta destaca-se a influência positiva da bacia do igarapé Ambé. Sendo este, fundamental para diminuição da média climática no perímetro urbano da sede do município, reconhecendo que o perímetro urbano foi intensamente modificado com a implantação da Usina Hidroelétrica de Belo Monte (UHEBM), que fomentou a expansão urbana.

A variação espaço-temporal da temperatura superficial da Bacia do igarapé Ambé, na data de 25/06/2011 apresenta a média de $27,7^{\circ} \mathrm{C}$, à área já consolidada urbana do município apresenta média de $31,6^{\circ} \mathrm{C}$, a variação entre os dois espaços é marcado pela diferença em $5^{\circ}$ aproximadamente. Outro sim, na data de 23/02/2014 a média da temperatura superficial da bacia é de $26,1^{\circ} \mathrm{C}$, por sua vez, a média das áreas urbanas consolidadas do referido ano é de $30^{\circ} \mathrm{C}$, variação de $4^{\circ}$ aproximados. Em 23/5/2015 a média de temperatura superficial da bacia foi de cerca de $27,8^{\circ} \mathrm{C}$, a média urbana das áreas consolidada foi de $30^{\circ} \mathrm{C}$, variação de $3 \cdot 2^{\circ} \mathrm{C}$, conforma mapa 02 . 

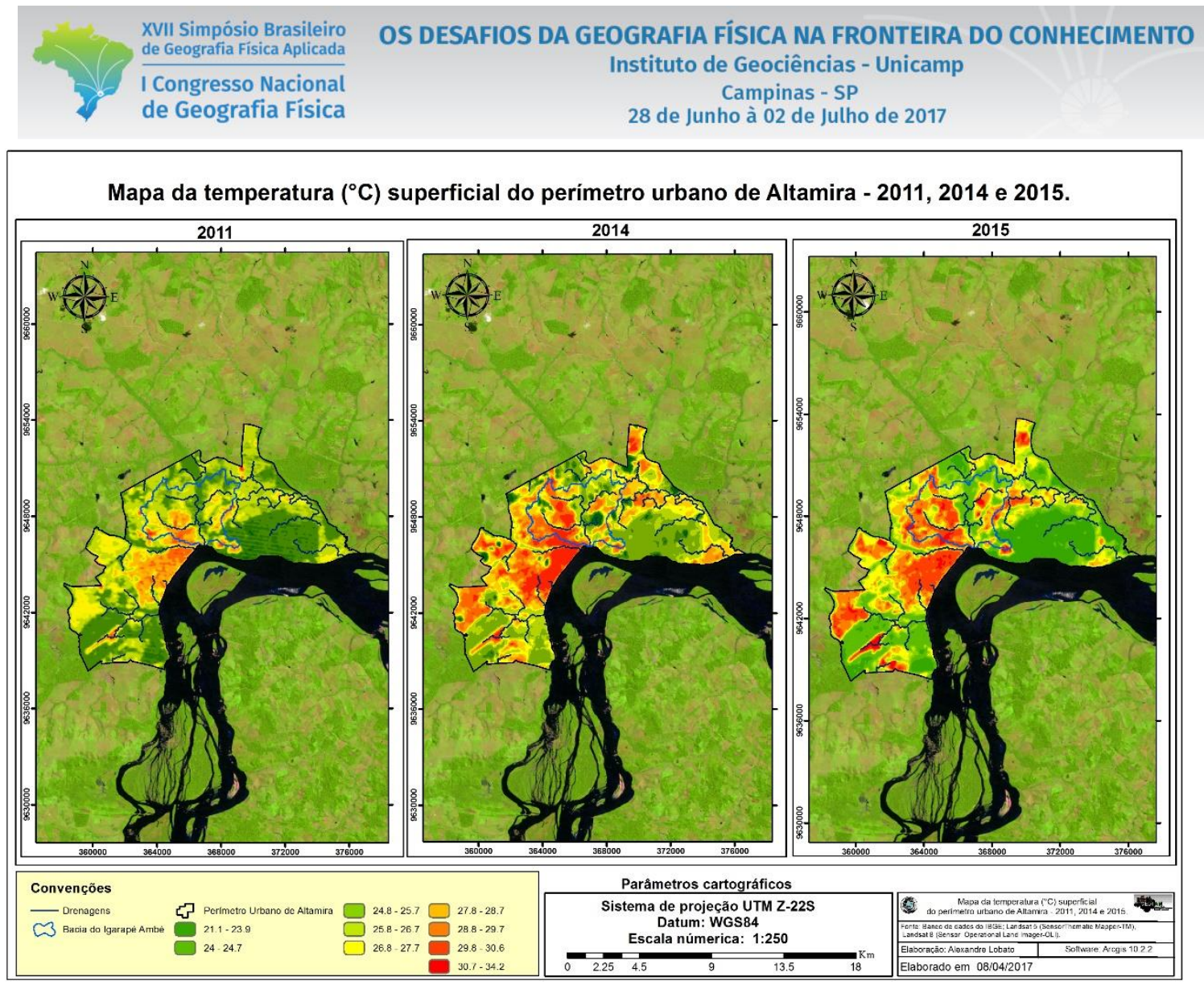

Mapa 02: Mapa espaço temporal da superfície.

O mapa 02, destaca a influencia do uso do solo, especialmente, da implantação do programa de requalificação urbana desenvolvido como condicionante para implantação e operação da UHEBM. Neste, o avanço do calor superficial no perímetro urbano de Altamira caminha de forma conjunta a ocupação dos novos espaços de intervenção e moradia.

\section{Considerações finais}

A energia incidente na superfície terrestre, em especial a Bacia do igarapé Ambé, é refletida (reflectância) em sua grande maioria na forma de calor sensível presente na faixa do infravermelho termal. Através deles obteve-se os resultados em caráter preliminar, indicando uma variação significativa na temperatura superficial na analise espaço-temporal. A bacia do igarapé Ambé apresentou temperatura superficial a mais baixa, quando comparadas às áreas urbanas consolidadas em toda serie pesquisada, indicando que a manutenção do curso fluvial desocupado e de seu complexo paisagístico parcialmente preservado contribuiu decisivamente para temperatura em destaque. Vale dizer que, o aumento da temperatura superficial se dá pelo aumento de moradias aos redores do perímetro da bacia ocasionado pela expansão do perímetro urbano e pela elevação do preço da terra no núcleo central. Por sua vez, a temperatura 
das áreas urbanas consolidadas obtiveram altas de cerca de $2^{\circ} \mathrm{C}$, mantendo-se nas faixas superiores a $30^{\circ} \mathrm{C}$, qual ratifica a implicação dos usos do solo na temperatura urbana, demonstrando a importância da bacia do igarapé Ambé, para manutenção do microclima urbano de Altamira, pois o balanço energético do calor absorvido e refletido contribui para amenização climática e sensação termina nas áreas próxima da bacia e mesmo no perímetro urbano de Altamira.

\section{Bibliografia}

ANDRADE, A. F.; BOTELHO, M. F.; CENTENO, J. A. S. Classificação de imagens de alta resolução integrando variáveis espectrais e forma utilizando redes neurais artificiais. XI Simpósio Brasileiro de sensoriamento Remoto. Anais. Belo Horizonte, Brasil: INPE, p. 265-272, 2003.

BERQUE, A (1984): Paysage-empreinte, paysage-matrice: eléments de problématique pour une géographie culturelle. L'Espace Géographique. 13 (4): 33-34.

BERTRAND, G; BERTRAND, C. Uma geografia transversal e de travessias: o meio ambiente através de territórios e das temporalidades. PASSOS, M. M. (organizador), Maringá: Ed. Massoni, 2009.

CÂMARA, Gilberto; DAVIS, Clodoveu; MONTEIRO, Antônio Miguel Vieira (org.). Introdução à Ciência da Geoinformação. São José Campos, Inpe, 2001.

CAMPANA, N. A. \& TUCCI, C. E. M. Estimativa de Áreas Impermeável de MacroBacias Urbanas. Revista Brasileira de Engenharia. Caderno de Recursos Hídricos, vol.12, n. 2, dez/1994.

CHRISTOFOLETTI, A. Morfologia do relevo na média bacia do Rio Corumbataí. In: Simpósio de Geografia Física Aplicada. São Paulo: Anais, 1994.

CHRISTOFOLETTI, A. A Análise de Bacias Hidrográficas. Geomorfologia. 2. ed.

CORRÊA, Roberto Lobato O Espaço Urbano. Editora Ática, Série Princípios, 3a. edição, n. 174, 1995.

FERRARI, J. L.; SANTOS, A. R.; GARCIA, R. F. Análise da vegetação por meio da subtração de imagem NDVI na sub-bacia hidrográfica do córrego do horizonte, alegre, ES. Engenharia Ambiental - Espírito Santo do Pinhal, v. 8, n. 3, p. 003-018, jul./set. 2011.

FERREIRA, M.J. Estudo do balanço de energia na superfície da cidade de São Paulo. 2010. 183 f. Tese (Doutorado em Meteorologia) - Universidade de São Paulo - Instituto de Astronomia, Geofísica e Ciências Atmosféricas, 2010.

FLORENZANO, Tereza Galloti. Iniciação em Sensoriamento Remoto. São Paulo: Oficina de Texto, 2011.

KÖPPEN, W.; GEIGER, R. Klimate der Erde. Gotha: Verlag Justus Perthes. 1928. Wall-map $150 \mathrm{~cm} \times 200 \mathrm{~cm}$

GRIGG, N.S. 1996. Water resources management: principles, regulations, and cases. McGraw-Hill Book Co., Inc., New York..

MANOSSO, F. C. Estudo Integrado da Paisagem nas Regióes Norte, Oeste e Centro-Sul do Estado do Paraná: relações entre estrutura geoecológica e a organização do espaço. Boletim Geografia, 2009.

MARQUES NETO, R. Considerações sobre a paisagem enquanto recurso metodológico para Geografia Física. Rio de Janeiro. Boletim de Geografia,

2008.

NOVO, E.M.L.M. Sensoriamento Remoto: Princípios e Aplicações. Ed. Edgard Blucher Ltda. 3a Edição, São Paulo, 2008. 363 p.

PAIVA, J. B. D. de; PAIVA, E. M. C. D. de. (Orgs.). Hidrologia aplicada à gestão de pequenas bacias hidrográficas. Porto Alegre: ABRH, 2001. $625 \mathrm{p}$.

ROSA, R.; Brito. J.L.S.; Lima. E.F.; Siqueira, C.A.; Macedo, D. Elaboração de uma

SILVA, C. S.; AUGUSTO, S. G.; ANDRADE, A. U. Caracterização agrometeorológica de Altamira, PA. SEMANA DE INTEGRAÇÃO DAS CIÊNCIAS AGRÁRIAS, UFPA, IX Altamira, PA: Anais... p. 148-154. 2009.

TUCCI, C. E. M. (Org.). Hidrologia: ciência e aplicação. 2. ed. Porto Alegre: ABRH, 1997. 943 p. 